\title{
Imaginarios femeninos a través de los discursos visuales del se- manario Sábado, Quito 1953-1966
}

\author{
Feminine imaginaries through the visual discourses in the weekly newspaper \\ Sábado, Quito 1953-1966
}

\author{
Analía Vallejo Larrea \\ Pontificia Universidad Católica del Ecuador \\ analiavala@hotmail.com
}

Fecha de recepción: 29 de noviembre de 2017

Fecha de aprobación: 23 de febrero de 2018

\begin{abstract}
Resumen
Este artículo analiza la sección "Deténgase aquí mujer" del semanario Sábado en el período de 1953 a 1966. Indaga la construcción de los imaginarios femeninos de la época, los aspectos que tienen una relación directa con las mujeres y los cambios que se han dado a lo largo del tiempo. El análisis muestra la estrecha relación de la mujer con la religión, el interés por parte de los varones de escribir sobre las mujeres y el vínculo de los imaginarios femeninos con la vanidad. También se puede ver repetidamente la importancia que tiene el rol de esposa fiel y de madre, consideradas como características indispensables de una mujer de la época.
\end{abstract}

Palabras clave: Imaginarios femeninos, siglo XX, Quito, Semanario Sábado.

\begin{abstract}
In this paper I analyze the section "Deténgase aquí mujer" of the weekly newspaper Sábado, in the period from 1953 to 1966 in order to investigate the construction of feminine imaginaries of that epoch, the aspects that have a close relation with women and the changes of it along the time. In the analysis I highlight the close relation of women with religion, the male interest on writing about women and the connection of female imaginaries with vanity. I also, as can be seen repeatedly, show the importance of the roles of both the faithful wife and the mother, considered as essential characteristics of a women of that time.
\end{abstract}

Keywords: Female Imaginaries, 20th Century, Quito, Sábado Weekly Newspaper. 


\section{Introducción}

El objetivo del presente trabajo es analizar la sección "Deténgase aquí mujer", del semanario Sábado, que fue publicada desde 1953 hasta 1966, y a través de la misma llegar a entender los cambios que se han generado en torno a la concepción de lo femenino. En este sentido esta investigación propone realizar un análisis semiótico e iconográfico sobre la historia del cuerpo de la mujer, evidenciada en dicha sección. Así, el trabajo establece una correspondencia entre "Deténgase aquí mujer" y la concepción femenina, mostrando la influencia de los medios de comunicación en la creación de un imaginario.

Dentro del Ecuador la persona que más se ha dedicado al estudio sobre estos temas es la socióloga e historiadora Ana María Goetschel, quien trabaja principalmente alrededor de los imaginarios y la educación femenina. ${ }^{1}$ Sus trabajos aportan a esta investigación, no solo porque se encuentran en el periodo escogido, sino también porque la autora trabaja sobre la formación de imaginarios femeninos; incluso trabaja con revistas, aspecto en el cual pretendo concentrarme para la realización de este artículo. Otra autora que se dedica a este tema es la historiadora Martha Moscoso, quien nos ayuda a la formación de un contexto dentro de lo que es la historia de la mujer.

A comienzos del siglo XX, tanto en Quito como en Guayaquil, se comienzan a publicar revistas que estaban orientadas específicamente para las mujeres. Estas revistas tuvieron una difusión relativamente restringida. Paralelamente a ellas circularon otras que, desde una visión masculina, representaron a las mujeres. Estas revistas, que representan el discurso dominante, serán analizadas en este trabajo para entender el imaginario visual, social y de género. Es importante entender que no ha existido un único modelo de ser mujer a lo largo del siglo XX; asimismo, las luchas femeninas ocupaban dos espacios distintos: el primero, que surge desde la elite, donde se exigía un lugar dentro de la política; y el segundo, que surge desde las mujeres obreras, las cuales exigían igualdad de salarios y un espacio para ver y poder amamantar a sus hijos.

La primera parte de este artículo se enfoca principalmente en el periódico, de dónde surge, hacia qué público estaba dirigido, que secciones contiene, etcétera. La segunda parte consiste en el análisis de la sección "Deténgase aquí mujer", buscando señalar los elementos que resultan decisivos dentro de la concepción de un imaginario. Finalmente, en las conclusiones se establecerá qué elementos conforman el imaginario femenino desde la mirada del periódico Sábado.

1 Ana Maria Goetschel, De Memorias imágenes públicas de las mujeres ecuatorianas de comienzos y fines del siglo XX (Quito: Trama, 2007). 


\section{Acerca de Sábado}

El trece de junio de 1953 aparece en Quito el primer número del semanario Sábado. Este periódico nace a partir de la clausura de otro. En la tercera presidencia de José María Velasco Ibarra, junto con su ministro de gobierno, Camilo Ponce, se cerró el diario liberal El Día, que en ese momento tenía más de 40 años. Los periodistas que trabajan para este diario, al encontrarse desempleados, decidieron crear un nuevo periódico, el semanario Sábado, que fue dirigido por Juan Paz y Miño Cevallos y Luis Maldonado Tamayo. Con estos antecedentes nos encontramos con su primer número, en tamaño tabloide, con doce páginas, y a un valor de un sucre. La posición ideológica de periódico quedaba clara a partir de la editorial inicial titulada "Aquí estamos":

Al amparo de la garantía constitucional, venimos a decir nuestra palabra verdadera y altiva. Estamos al lado de la libertad y de la democracia. Vamos a caminar junto al pueblo, codo con codo con las mayorías. Nuestro primero y principal objetivo es contribuir al engrandecimiento de la Patria común, después pretendemos elevar o interesar al hombre ecuatoriano por la cultura, el arte y por las ciencias, por la belleza en fin. No venimos con gesto severo, y más bien queremos vivir por y para la alegría. Entregamos este semanario a la conciencia liberal y a las ambiciones por alcanzar la justicia plena. $\mathrm{Y}$ al hacerlos tendemos la mano a la prensa independiente del país, cuyo ejemplo de ponderación seguiremos, con celo y optimismo. ${ }^{2}$

En esta primera editorial podemos evidenciar el sentimiento que dejó la clausura del periódico El Día, las ganas de luchar por la libertad de expresión y la oposición existente hacia el gobierno de Velasco Ibarra. Juan Paz y Miño escribía: "Sábado viene a remplazar una voz de libertad y patriotismo. Mientras El Día tenga que permanecer en silencio, nuestro semanario seguirá su tarea de enjuiciamiento a la dictadura velasquista" 3 . De esta manera, entendemos de dónde nace el periódico y podemos reconocer este resentimiento hacia la opresión y la oposición hacia el gobierno a lo largo de sus páginas. A lo largo de los años se ve la defensa de la razón y las libertades en escritos y caricaturas, utilizando la analogía de Velasco Ibarra como un ser que se cree superior, que se siente mesías en una sociedad atrasada, como un "Quijote crio1lo", con Camilo Ponce como su Sancho.

Bajo el lema "la verdad en una semana", Sábado en su primera etapa publicó 30 números. Aparte de la defensa de la libertad de expresión ante el gobierno de Velasco, que se encontraba en la sección de crónica política, también podemos encontrar un espacio marcado para la información cultural, económica y turística, incluso un

2 Isabel Paz y Miño, "Los periódicos que enterré,” en 50 años de periodismo (Quito: Banco Central del Ecuador, 2010), 83.

3 Paz y Miño, "Los periódicos que enterré," 83-4. 
espacio para la información taurina a cargo de Oswaldo Paz y Miño, quien también se encargaba de las secciones de economía y turismo. En estas primeras ediciones podemos encontrar un tema que es evidenciado en la mayoría de sus números, me refiero al conflicto con el Perú, tema que se encontraba en auge, y que fue tratado por el semanario. La publicidad que financiaba en parte el semanario era de librerías, radioemisoras, almacenes, negocios, y, especialmente, los despachos profesionales que apoyaban la causa periodística: "Wilfrido Loor, Ricardo Izurieta, Guillermo Bossano, Enrique Echeverría, Plutarco Naranjo, Alfredo Pérez Guerrero"4. La primera etapa de Sábado concluyó por problemas económicos, lanzando su número 30 el 16 de enero de 1954, antes de cumplir un año.

El semanario reaparece casi una década después, el 25 de agosto de 1962, en un momento de crisis nacional, se trata del juicio político hacia el presidente Carlos Julio Arosemena, tema tratado en el semanario, sin dejar a un lado la posición política de los escritores y sus opiniones, en este sentido también encontramos como el semanario desenmascara a los "padres de la patria" exponiendo el hecho de que un profesor con 20 años de experiencia gana menos que un congresista en cuatro días, teniendo estos un sueldo de 1600 sucres al mes. ${ }^{5}$ De esta manera, el periódico nos muestra las diferentes realidades del país y denuncia la enorme desigualdad existente. Sin embargo, el semanario aparte de ser un periódico político, de análisis y reflexiones en torno a acontecimientos sobre la vida nacional, también era un medio de humor; de humor negro específicamente. Contaba con una sección, la cual era la más leída, denominada: "para matar el sábado". Esta se encontraba en la última página y recogía chistes originales de quienes conformaban el cuerpo de redacción. El periódico siempre fue hecho pensando en su público, en decir la verdad y compartir la información, sus autores no veían al semanario con intereses económicos, ya que prácticamente no ganaban nada con su distribución, esto lo podemos evidenciar cuando Juan Paz y Miño escribe celebrando el tercer aniversario del periódico:

Hacemos periodismo por convicción, por necesidad espiritual, por servicio público. No dependemos de nadie; nadie nos censura ni nos impide escribir. Lealmente creemos no habernos alejado de nuestra promesa inicial: ser eco del pueblo, defender las buenas causas del país. Esta conducta y nuestra palabra severa, nos ha ganado millares de lectores con cuya compañía vivimos y generosos amigos, cuyos anuncios financian Sábado. A nosotros nos queda la satisfacción de hacer acaso lo único que podemos: un periódico. La aspiramos, pero mientras llegue, si llega, tenemos resolución suficiente para continuar esta tarea. ${ }^{6}$

\footnotetext{
$4 \quad$ Paz y Miño, "Los periódicos que enterré," 92.

$5 \quad$ Paz y Miño, "Los periódicos que enterré," 157.

6 Paz y Miño, "Los periódicos que enterré," 163.
} 
Lo que ganaban con la venta del semanario lo invertían para su siguiente edición. Ninguno de los escritores del periódico veía al mismo como su trabajo fijo, y este era realizado por las noches. Por ejemplo, los miércoles se reunían en la noche para ver qué chistes iban a ser colocados en su sección "para matar el sábado". Sabemos que este semanario realmente no tenía mayor alcance, solo se distribuía en la ciudad de Quito, los ejemplares que no se llegaban a vender el sábado eran vendidos el domingo en el estadio. Raúl Paz y Miño nos cuenta como se realizaba la distribución:

El semanario estaba listo el sábado a las cuatro de la mañana. Yo cargaba el paquete de dos mil o tres mil ejemplares hacia la esquina de correo, en la calle Chile, que era uno de los puntos de distribución. Allí los voceadores esperaban El Comercio, que salía también a esa hora. No había que convencer a los canillitas del diario para que aceptaran llevar también Sábado. Lo hacían porque la gente compraba, les encantaba nuestro periódico, y porque se pagaba bien por ejemplar vendido a los voceadores. ${ }^{7}$

En conclusión, nos encontramos ante un periódico que germina a partir de la opresión, donde se busca decir siempre "la verdad"; nos encontramos ante la prensa chica que sueña con ser grande, ante periodistas que no pretenden volverse millonarios sino, en cambio, ser leídos por todo el país, ante un semanario que no cuenta con mayor ingreso, más que el de las publicidades que se encuentran en él. Estamos ante la prensa independiente que se define claramente como liberal, la cual decide crear un espacio para la mujer, este espacio podría ser visto como un elemento inclusivo de parte del pensamiento liberal, o un espacio creado para atraer más público y tener más lectores y compradores, o un espacio para fomentar el conocimiento del sector femenino. La verdadera razón por la cual los editores del semanario Sábado deciden escribir la sección "Deténgase aquí mujer" es incierta; sin embargo, es indudable que esta sección nos brinda mucha información sobre los imaginarios femeninos de la época.

\section{"Deténgase aquí mujer"}

La primera edición de la sección "Deténgase aquí mujer" sale el 20 de junio de 1953; es decir, en la segunda publicación del semanario. Esta estaba divida en cuatro espacios: un poema de César Andrade y Cordero, un escrito de Severo Catalina, una sección donde se muestra a la madre católica del año, y una sección donde se habla de Santa Cecilia, una mujer musical. El logotipo de dicha sección era muy simple, aunque posteriormente podemos ver una evolución. Encontramos un perfil dentro de una figura ovalada, se deduce que el perfil es femenino por la delicadeza de su contextura, también podemos encontrar decorados dentro de las letras de la palabra "mujer".

\footnotetext{
7 Paz y Miño, “Los periódicos que enterré," 173.
} 
Comencemos con el escrito de Severo Catalina. Él fue un periodista y escritor español que nació en Cuenca en 1932 y dedicó gran parte de sus escritos a la mujer como objeto de estudio. El texto presentado en el periódico pertenece a la introducción del libro La Mujer en las diversas relaciones de la familia y de la sociedad. Apuntes para un libro publicado en 1858; es decir, prácticamente un siglo antes. Esto produce varias preguntas: ¿acaso la problemática de la mujer se quedó estancada en el siglo XIX, o es que estos escritos recién llegaban al país? Es definitivamente significativo que publiquen un texto tan antiguo, ya que no solo nos muestra que la búsqueda de una definida separación entre la mujer y el hombre se daba desde hace mucho tiempo, sino que sí se publican estos pensamientos, quiere decir que los imaginarios femeninos no han cambiado mucho en un siglo; sin embargo, esta no es la realidad. No sabemos con exactitud cuántas mujeres leían esta sección, pero sí sabemos que los editores del periódico eran todos hombres que escribían específicamente para el sector femenino; es decir, buscaban temas que ellos suponían interesaban a las mujeres como: "La ciencia de la mujer se parece mucho al patriotismo y al desinterés; muchos hablan de ellas y pocos las poseen". Las mujeres se leen como objeto de estudio, los hombres escriben sobre ellas desde la "otredad". Severo Catalina dedicó gran parte de su libro al tema de la educación femenina, diciéndonos que en el siglo XIX "la niña aprende á disimular, y enseña más tarde á la mujer á engañar, Aprende á afectar silencio, y ese germen de aceptación produce luego el amargo fruto de la locuacidad. Aprende á estimar en mucho sus dotes de hermosura y su condición de mujer; y esa ciencia peligrosísima trae por legítimos corolarios el orgullo y la coquetería, la frivolidad y la inconstancia". Catalina concluye que este problema debería resolverse si es el marido el que educa a su mujer. Es esta la línea de pensamiento que se publicaba para que las mujeres pudieran leerlo, y es este probablemente el pensamiento que continuaba definiendo la época, y a partir del cual se construyen los imaginarios femeninos.

Dadas la condiciones de la actual sociedad, no es preciso que la mujer sea sabia: basta con que sea discreta: no es preciso que brille como filósofa: le basta con brillar con su humildad como hija, con su pudor como soltera, por su ternura como esposa, por su abnegación como madre, por su delicadeza y religiosidad como mujer. ${ }^{10}$

Por otra parte, nos encontramos con el título "Madre católica del año". Debajo de una fotografía el texto nos habla sobre la señora Ann Mary Kirn Hoffer, una dama de Kentucky, de 66 años de edad, que ha sido seleccionada como la madre católica del año, ya que ha dado cinco de sus seis hijos a la vida religiosa. La elección se dio por parte de la Conferencia Católica Nacional para la Familia en 1953. En la fotografía

8 Término utilizado por Tzvetan Todorov.

9 Catalina Severo, La mujer: apuntes para un libro (Madrid, 1858), 15.

10 “Deténgase aquí mujer," Sábado, junio 20, 1953, 2. 
se puede ver a la señora Hoffer junto a su esposo, Alphonse J. Hoffer, y entre ambos a su nieta Mary Hoffer. En la fila de atrás están sus hijos: la hermana Mary Felician, la hermana Mary of the Trinidad, su hijo Ralph Hoffer junto a su esposa y su bebé, el padre Charles Hoffer, el padre Ranan Hoffer, y el padre Francis X. Hoffer, todos franciscanos. Resulta interesante pensar de dónde se obtuvo esta fotografía y la información, ¿qué conexión tenía Ecuador con Estados Unidos? En este momento Estados Unidos se comenzaba a posicionar como potencia mundial, a partir de la Segunda Guerra Mundial, si nos fijamos en la imagen, podemos ver que al final del texto existe una referencia que dice "(Gráfica USIS)", esta se refiere a la Agenda Informativa Norteamericana que era publicada desde la Embajada de los Estados Unidos en Quito, con Roy Johnson como director de prensa de la época. Es decir, esta información fue divulgada desde la Embajada y los redactores de Sábado la utilizaron al considerarla un tema interesante para el sector femenino.

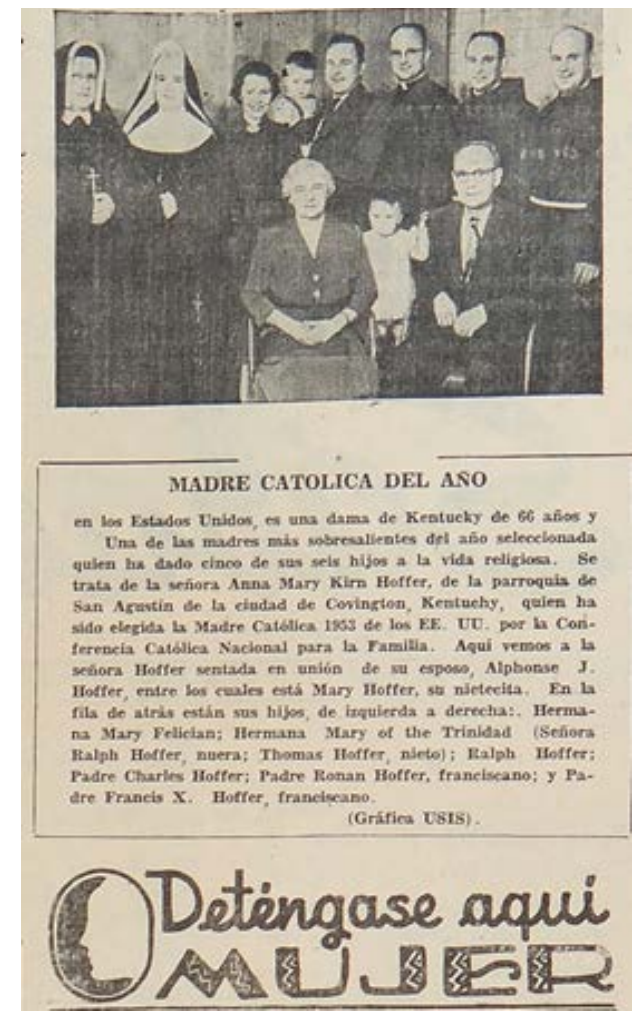

Ilustración 1. Madre Católica del año. (20 de junio de 1953). Sábado, pág. 2

Este pequeño apartado nos otorga mucha información. Primero, debemos entender que la Iglesia continúa teniendo gran poder sobre la sociedad. Segundo, sabemos que la religión sigue siendo un tema que tiene una relación más directa con las mujeres, recordemos que este semanario se autodefine como "liberal"; por lo tanto, este apartado genera un contraste con la ideología del periódico, cabría aquí preguntarse 
en dónde queda lo liberal: ¿En el mundo político? ¿En la vida pública?, mientras que en el espacio doméstico se sigue apelando a la religión como fuente de valoración y sujeción de las mujeres, vemos que dentro de este espacio el conservadurismo funciona como base inquebrantable. Finalmente, es necesario hablar sobre la importancia de la figura materna dentro de los imaginarios femeninos, la maternidad es incluso utilizada como un recurso de las propias mujeres para lograr una valoración social y negociar un espacio en la vida pública.

Se puede evidenciar, en los discursos de la época, un sentido enaltecedor hacia la maternidad y hacia el papel de la mujer en el hogar y en la familia. Desde de la tercera década del siglo, en concordancia con las políticas de crecimiento poblacional, la población infantil y la maternidad fueron parte de la preocupación estatal. Así, nos explica Goetschel: "La visión tradicional de la mujer como madre encargada de alimentar, cuidar y sanar, adquirió especial interés cuando se puso al servicio de la nación, proceso que parece haberse dado, también en otros países de América Latina"11. En este contexto el territorio latinoamericano era descrito como despoblado y vacío, con una gran cantidad de niños que morían, por lo tanto, la maternidad comenzó a plantearse como un problema nacional y como un tema público. En el Ecuador esta búsqueda de protección a la maternidad se dio desde los informes oficiales del Estado; el crecimiento de la población fue identificado como una prioridad nacional, el cuidado de la vida $y$, por ende, el de la madre y el niño fueron considerados fundamentales. "La población misma del país empezó a ser percibida como una de las fuentes principales de riqueza nacional" 12 . Esto se debe, a su vez, a las altas tasas de mortalidad infantil, que alcanzaba el 50\% en niños nacidos vivos, y de aquellos solo el 25\% llegaba a los siete años. ${ }^{13}$ Todas estas políticas van de la mano con la idea, que se comienza a implantar, del Estado como dador de empleo y bienestar, plasmada por el economista John Maynard Keynes.

Dentro de la primera edición de "Deténgase aquí mujer" encontramos un apartado dedicado a Santa Cecilia, donde se muestra la historia de su vida. ${ }^{14}$ La sección "Deténgase aquí mujer" cambió mucho durante sus siguientes ediciones; sin embargo, hay dos espacios que parecen repetirse a lo largo del tiempo, y son el espacio dedicado

11 Goetschel, De Memorias imágenes públicas de las mujeres..., 42.

12 Kim Clark. "Género, raza y nación: La protección a la infancia." En Antología Género. Gioconda Herrera (Quito: FLACSO, 2001), 185.

13 Goetschel, De Memorias imágenes públicas de las mujeres..., 44.

14 Santa Cecilia es mostrada como mujer musical, ya que es patrona de la música. El autor del artículo nos cuenta que el cadáver de Cecilia fue encontrado en 1599 por el Cardenal Sfrondati en Roma, y estaba "cual si acabara de morir" (murió en el año 230). El periódico nos cuenta que Santa Cecilia fue obligada a casarse con Valeriano, un pagano; sin embargo, en la noche de bodas Cecilia le dice a Valeriano que ella tiene un Ángel que está encargado de velar por su virginidad. Su marido le contestó que él va a creer en Jesucristo si ve a aquel Ángel; pero Cecilia le dice que eso no va a ser posible mientras él no esté bautizado. Por ende Valeriano fue bautizado y, enseguida, pudo ver a un hermoso Ángel cuidando de su mujer. La fecha de recordación litúrgica de Santa Cecilia es el 22 de noviembre, fecha donde se celebra, en algunos países, el día de la música. 
específicamente a la religión, que como se ha dicho antes se encuentra ligado hacia la mujer más que hacia el hombre, y el espacio dedicado a la poesía.

En este caso nos encontramos con un poema de Cesar Andrade y Cordero denominado Canción Absurda del Recuerdo. En esta época era muy común encontrar publicaciones literarias en los periódicos, sobre todo poesía, el oficio de escritor y periodista generalmente iban de la mano. Es interesante ver cómo la poesía entra dentro de esta sección, al ser considerada un elemento que llega a ser interesante para las mujeres. A partir de esta primera edición ya podemos obtener algunas ideas sobre las bases en las que se comienzan a construir los imaginarios femeninos. En primer lugar, sabemos que existe un interés de los hombres por escribir sobre las mujeres, estudiarlas, analizarlas desde el "otro cultural", desde el ser distinto. En segundo lugar, sabemos que la conexión con la religión es muy marcada; la Iglesia tiene mucho poder sobre las mujeres. Finalmente comprendemos que la maternidad es fundamental desde los imaginarios de la mujer, ya que se concibe a la mujer como hecha para ser madre.

Un mes después de esta primera edición, el 11 de julio de 1953, aparece una sección que, pese a no ser parte de "Deténgase aquí mujer", llega a ser fundamental dentro de este trabajo. Se trata de un apartado donde se explican las proporciones perfectas de una mujer. El autor cuenta cómo las mujeres tienen una serie de reglas fijas para determinar el ideal de las proporciones de la mujer. De igual forma pide a sus lectoras que lo comprueben si lo desean:

La figura debe tener siete y media veces la longitud de la cabeza.

El cuello una tercera parte del largo de la cabeza.

... Los hombros tres veces la anchura de la cabeza,

El busto, en la parte más ancha, debe estar en líneas con la parte de debajo del brazo, o un poquito más bajo.

La cintura debe ser aproximadamente dos terceras partes de la altura total desde el suelo.

Las caderas deben tener la anchura de un brazo más que el busto. ${ }^{15}$

Evidentemente las percepciones del "cuerpo ideal" cambian con los tiempos, al igual que la idea de belleza. Sin embargo, el hecho de que exista una idea de perfección en cuanto al cuerpo femenino, el cual cuenta con medidas exactas, no ha cambiado mucho, el cuerpo llega a ser un objeto, el cual es juzgado socialmente creando modelos de perfección. La búsqueda del significado de la belleza ha sido estudiada desde Platón hasta Gadamer; sin embargo, nunca se llega a una respuesta concreta. A lo largo de la historia se ha relacionado a la idea de mujer con la idea de belleza. En estos momentos podemos evidenciar que se ve al cuerpo como un objeto de consumo, un objeto perfectible.

15 "La mujer: las proporciones ideales," Sábado, julio 11, 1953, 2. 
Los constructivistas como Douglas, Foucault, Goffman y Turner toman el cuerpo como algo que pertenece a la cultura y no a una identidad biológica. ${ }^{16}$ En este sentido, si vemos al cuerpo interpretado culturalmente, podemos hablar también de la regulación hacia el cuerpo. Porter nos explica que existe un estereotipo cultural profundamente arraigado dentro de la teología cristiana que presenta el cuerpo corno "un anarquista, el rey de la juerga, emblema de los excesos en la comida, la bebida, el sexo y la violencia -la encarnación del principio que Freud intelectualizó más tarde en el «ello»" "17. Ante esta idea podemos ver cómo desde ciertos grupos sociales dominantes se busca restringir, reprimir y reformar los excesos del cuerpo, si bien este no es el caso de una regulación moral ante los excesos, sí nos encontramos ante una regulación, ya que se están planteando las medidas ideales del cuerpo las cuales deberían poder ser alcanzadas.

En este número también aparece la primera edición del "Consultorio Sentimental", por el profesor Casanova. En esta apartado, una mujer escribe pidiendo consejos, principalmente relacionados con las relaciones amorosas. Quizá se podría pensar que en este momento por primera vez podríamos estar hablando de la voz de una mujer; sin embargo, no existe evidencia suficiente para hacer esta afirmación, ya que muchos periódicos y revistas, incluso actualmente, se inventan este tipo de historias para generar una trama interesante para el público lector. Al no haber encontrado anteriormente algún anuncio sobre este espacio, el cual sí aparece en los años posteriores, o alguna dirección o referencia donde se envíen las dudas de las muchachas, debo decir que lo más probable es que se trate de alguno de los propios redactores del periódico, sin embargo, vale la pena mencionarlo por la información que este nos brinda.

ACUDO A USTED en un trance duro, imprevisto para mí. Siempre he sido una mujer honesta que nunca pensó más en su marido, y en su hogar, pero, he aquí, que a mi casa ha venido un inquilino que, por todos los indicios está enamorado de mí. Mi angustioso problema es que mentalmente he admitido este amor: fijese, profesor, he comenzado a hacer comparaciones entre mi marido y el inquilino. Desde luego el balance es favorable para el "intruso"

Posteriormente Sofía, la mujer, sigue contando cómo trata de huir de dicho hombre. Dice que él es soltero inteligente y de buen físico, y duda sobre estar enamorada. Finalmente termina pidiendo ayuda, diciendo que la experiencia y los años de Casanova la han hecho confiar en él.

$16 \quad$ Ana Martínez Barreiro, "La construcción social del cuerpo en las sociedades," Papers 73 (2004), 128.

17 Roy Porter. "Historia del cuerpo" En Formas de hacer historia, Ed. Peter Burke,. (Madrid: Alianza Editorial, 1993), 271.

18 "Consultorio sentimental," Sábado, julio 11, 1953, 2. 


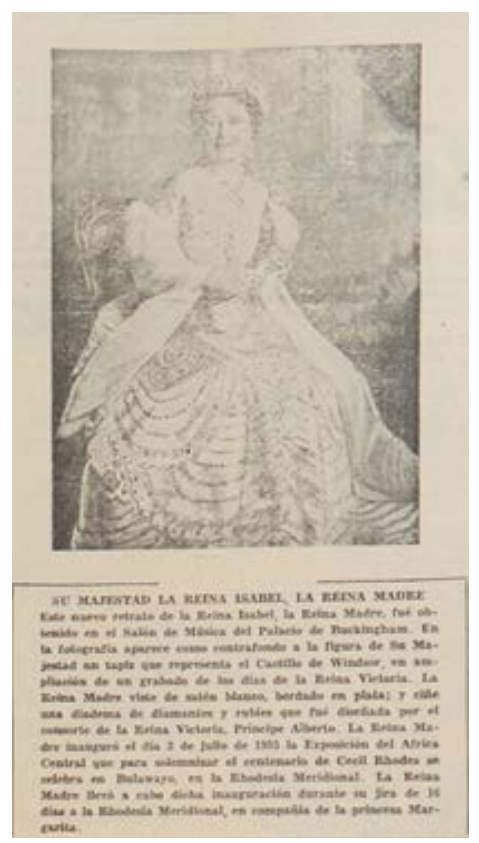

Ilustración 2. : Sábado. «Consultorio Sentimental.» 11 de Julio de 1953: 2.

Las relaciones monogámicas se han implantado desde la colonia, y son parte básica del pensamiento occidental. La infidelidad ha estado relacionada con la lujuria, uno de los pecados capitales que inexorablemente conducen al infierno. Sin embargo, esta ideología está dirigida sobre todo a las mujeres pues se considera que ellas pueden dominar sus "instintos carnales", mientras que los hombres son vistos como seres sexuales que son más propensos a caer ante las tentaciones. La respuesta del profesor consiste en decirle que considera que ella está más enamorada de lo que piensa, y su consejo es que le saque al inquilino de la casa para evitar problemas. Sin embargo, algo que llama la atención es que al terminar su consejo dice "no es usted una chiquilla, ni una mujer libre". Es decir, que se concebía que en el momento en que una mujer contraía matrimonio perdía su libertad; una mujer casada debía ser sumisa y obediente ante su marido, era parte del ser mujer. El uso de la palabra libertad llega a ser muy fuerte en este sentido, prácticamente se está diciendo que la mujer carece de ella por estar casada.

Además del consultorio sentimental nos encontramos con un apartado dedicado a la Reina Isabel. En este apartado se habla principalmente de esta fotografía, lamentablemente el deterioro del papel y el desgaste de la tinta no nos permiten evidenciar todo lo que el escrito nos cuenta. El retrato fue tomado en el Salón de Música del palacio de Buckingham, en el fondo se encuentra un tapiz que representa el Castillo de Windsor, en ampliación de un grabado de los días de la Reina Victoria. La Reina está usando un vestido de satén blanco bordado en plata, y tiene una diadema de diaman- 
tes y rubíes. La Reina Madre inauguró el 3 de julio de 1953 en Bulawayo, Rhodesia Meridional, la exposición del África Central para solemnizar el centenario de Cecil Rhodes. Esta noticia se publicó el 11 de julio de 1953, una semana después de lo acontecido en Europa, lo cual muestra que la información llegaba muy rápido. A diferencia de la fotografía sobre la Madre Católica del año, en esta no sabemos de dónde proviene la información, ni cómo se obtuvo la fotografía; no existe ninguna referencia.

Es interesante cómo el periódico busca siempre publicar en esta sección noticias del exterior, se ve constantemente hacia fuera, y las mujeres que sirven como referencia para las lectoras son extranjeras. También hemos visto cómo este apartado se ha dedicado a publicar mujeres reconocidas mundialmente, creando un "ideal de cómo me gustaría ser". Además, esto nuevamente contrasta con la ideología del periódico, supuestamente liberal, que presenta como ideal de mujer a una Reina, contradiciendo la tradición anti-monárquica del liberalismo. La idea de búsqueda contante de referentes en el exterior la podemos evidenciar también en otras secciones como, por ejemplo, un artículo que dice " 4 de julio, fecha de la libertad de Norteamérica y del Mundo". Para finalizar la sección se encuentra un poema de Gonzalo Escudero titulado Mujer Deshabitada.

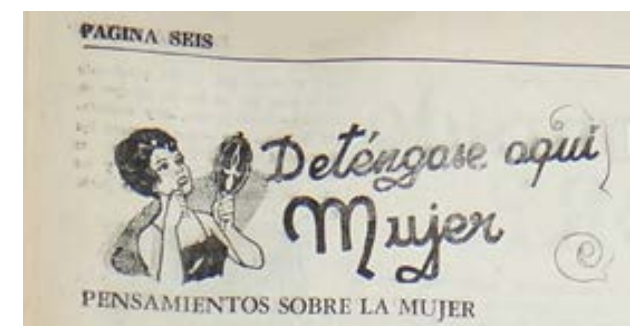

Ilustración 3. : Decálogo de belleza . (25 de agosto de 1962). Sábado, pág. 6.

Cuando reaparece el periódico, el 25 de agosto de 1962, vuelve nuevamente la sección "Deténgase aquí mujer", esta vez renovada. El logo de dicha sección ahora cuenta con la imagen de una mujer sosteniendo un espejo y pintándose los labios. Si antes la sección se dedicaba a la vanidad femenina y a decir cómo ser mejor, ahora aumenta, esto se puede evidenciar desde el logo. Un logo es una expresión simbólica, en este caso creada para llamar la atención de las mujeres, desde aquellos símbolos que se consideran estar relacionados con ellas: el espejo y el labial. Se puede afirmar que se relaciona a la mujer con la vanidad. Abajo del logo se encuentra una sección denominada "Pensamientos sobre la mujer". Después de una década de la primera edición se mantiene la idea de que a las mujeres les va a interesar leer escritos sobre ellas, no son pensamientos de ellas. Se trata de una concepción que se asienta en la idea de que a ninguna mujer le interesaría leer pensamientos de mujeres, sino pensamientos sobre ellas, pensamientos que surgen desde el otro, desde este ser diferente que es el hombre, pero teniendo como objeto de estudio a la mujer. Uno de los "pensamientos" 
aquí escritos dice "Las mujeres perdonan las infidelidades. Pero no las olvidan. Los hombres olvidan las infidelidades pero no las perdonan". Nuevamente nos encontramos con la idea de dos mundos opuestos entre el ser hombre y el ser mujer. Generalización que nos muestra que todos los hombres en el mundo son y actúan de tal forma y lo mismo con respecto a las mujeres lo encontramos evidenciado a lo largo de las páginas del semanario, e incluso en la actualidad. Otro de los "pensamientos" que podemos encontrar en este apartado dice: "Todas las mujeres tienen igual condición y defectos: todas son idénticas; se dividen solamente entre morenas y rubias". Esta frase demuestra la cosificación que se producía con las mujeres, no solo existe tal punto de generalización que la única división consiste en si son morenas o son rubias, sino que también evidencia que la mujer no es más que lo que muestra por fuera.

Seguido de los "pensamientos sobre la mujer" nos encontramos con un espacio dedicado a los "consejos para la ama de casa". En este espacio encontramos desde consejos para mantener y reparar los azulejos hasta cómo terminar con un avispero. También hay un remedio contra la hidropesía, esto nos indica que es probable que haya sido una enfermedad popular en la época. Al final de los "consejos" nos encontramos nuevamente con los ideales del cuerpo perfecto, diez años después se publica la misma idea, pero ya no nos dice los mismo: "Las proporciones ideales de una belleza de nuestros días son: Talla: 1.65 metros; Muñeca 15 ctms. Pecho: 85; Cintura: de 65 a 67 (20 centímetros menos que el pecho); Caderas: de 85 a 87; Pantorrilla, de 28 a 32 (de 8 a 12 centímetros más que el tobillo); y tobillo: 20 centímetros" ${ }^{\prime 19}$. Es muy probable que los redactores consideraran fundamental el entendimiento del cuerpo ideal, para que lo hayan publicado más de una vez. Es tan intenso el dominio sobre el cuerpo que se impone un único tipo de belleza, el cual debe cumplir con las medidas exactas, para no quedar fuera del estereotipo de belleza establecido. No solo existe una generalización entre el ser hombre y el ser mujer, sino que existe una generalización sobre la belleza, aplicada únicamente al sector femenino, ya que hasta ahora no hemos encontrado un escrito sobre qué medidas deben tener los hombres para ser considerados bellos.

Con la imagen renovada, los redactores del semanario también deciden crear un nuevo apartado, el cual consiste en un álbum social femenino, este radica básicamente en lo que ya hemos visto, imágenes de mujeres que son reconocidas y que representan referencias para la "mujer común". Sin embargo, esta vez se presenta a una mujer ecuatoriana: la Primera Dama del Ecuador de ese entonces, Gladys Peet de Arosemena Monroy, quien está cumpliendo un positivo bien social a través del Patronato del Niño. La idea de utilizar mujeres famosas, que cumplieran con los ideales de la mujer que se quiere representar es utilizada también actualmente. En las portadas de revistas femeninas siempre va a aparecer una mujer que cumpla con los imaginarios que la

19 “Consejos para la ama de casa,” Sábado, agosto 25, 1962, 6. 
revista pretende impulsar, que supuestamente representan los ideales femeninos que se proyectan a futuro.

Debajo de este apartado se encuentra un poema del famoso escritor ecuatoriano Jorge Carrea Andrade, Zona Minada, y al final de la página hay un decálogo de belleza:

He aquí el DECALOGO DE LA BELLEZA; Primero: Brillo natural en los ojos. Segundo: cabello espeso y reluciente. Tercero: tez tersa y sonrosada. Cuarto: dientes blancos; Quinto: barbilla limpia y sin papadas; Sexto: cuerpo esbelto y ágil; Séptimo: manos finas y suevas. Octavo: espíritu alegre y optimista. Noveno: voz suave y sin afectación, y Décimo: Naturalidad al caminar. ${ }^{20}$

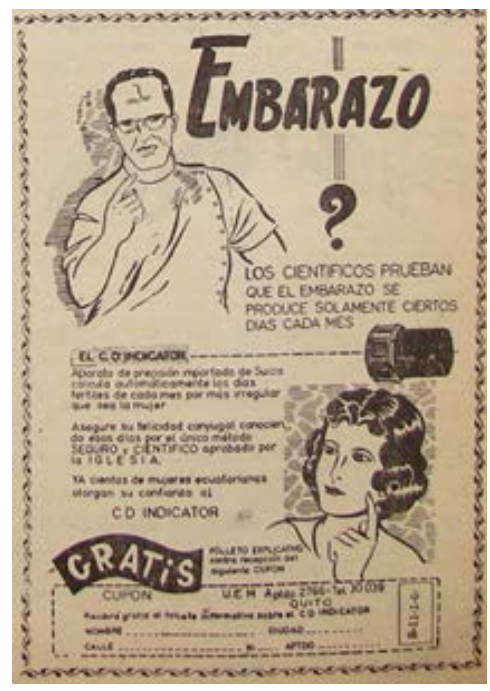

Ilustración 4. Emabarazo?. (11 de enero de 1964). Sábado, pág. 7.

La insistencia con los ideales de belleza, que se encuentran desde en el logo hasta en los diferentes aparados, dan cuenta que la base fundamental de los imaginarios femeninos y la primera idea con la que se relaciona a una mujer es la idea de belleza. Una mujer debe ser, antes que nada, hermosa, y es por esta razón que el semanario se preocupa tanto por dar consejos a la mujer para que sea más bonita, porque si la mujer se siente bonita se sentirá realizada y de esta forma agradecerá a los redactores del semanario por causarle dicha sensación.

Finalmente, para terminar con esta página, el segmento de "Consultorio Sentimental" también se renueva, ahora no es el profesor Casanova el que responde las cartas, sino el profesor Jean Merci, y en este momento la columna se llama "Respuestas a su corazón". En este apartado no se especifica cómo funciona el procedimiento para mandar las dudas escritas, solo dice que la dirección de Sábado se responsabiliza de guardar absoluta reserva sobre las consultas, donde se evidencian las inquietudes

"Decálogo de belleza," Sábado, agosto 25, 1962, 6. 
y dulces ilusiones de las lectoras, las cuales llegan a las mesas de redacción del semanario. Es importante aclarar que en las ediciones de esta columna no solamente han sido mujeres las que necesitan consejos, sino que también existen cartas de hombres, aunque en menor medida.

En una de las páginas del semanario, del 11 de enero de 1964, encontramos una publicidad que resulta bastante interesante, el producto que se busca vender consiste en un dispositivo que detecta en qué días la mujer se encuentra ovulando, esto representa un hallazgo científico y la introducción de la modernidad tecnológica en el Ecuador. Este dispositivo, denominado "C D INDICATOR", es importado desde Suiza y asegura calcular inmediatamente los días fértiles de la mujer, por más irregular que esta sea. Es importante rescatar que la publicidad resalta el hecho de que este dispositivo está aprobado por la Iglesia, y asegura que es el camino para asegurar la felicidad conyugal, porque si la esposa no queda embarazada no solo no se realiza como mujer, sino que no va darle la felicidad que merece su marido. La publicidad cuenta con un cupón que permite obtener gratis un folleto que cuenta con toda la información del "C D INDICATOR".

Este apartado publicitario tiene un valor iconográfico y simbólico muy importante. En primer lugar, nos encontramos ante esta imagen de un hombre científico (probablemente un doctor), que representa la idea del saber y el conocimiento. Este hombre se encuentra encima de la mujer, y ella aparece poniendo atención y recibiendo dicho conocimiento. Vemos que la imagen del hombre es más y grande y ocupa más espacio que la de la mujer, a pesar que este sea un producto para el sector femenino. Aquí evidenciamos sin duda una relación de poder. Fijémonos en la posición de la mano del médico; está dando una lección, es el maestro, el que enseña, el que transfiere conocimientos a los ignorantes.

Este nuevo aparato capaz de calcular en qué días se encuentra ovulando la mujer, no es solo una muestra de la introducción de una nueva modernidad en el país, sino son descubrimientos que llegan a ser fundamentales dentro de la historia de las mujeres. Sabemos que durante la historia los médicos, teólogos y filósofos, tradicionalmente varones, atribuían la subordinación de las mujeres a su condición biológica inferior en el esquema de la creación. "Según Aristóteles y sus seguidores, las mujeres son varones deficientes o monstruosos, seres cuyos genitales (previstos para estar situados fuera del cuerpo) no han logrado emerger por falta de calor y fuerza" ${ }^{21}$. Con su naturaleza, más fría y débil, y sus genitales retenidos en su interior, las mujeres estaban dotadas fundamentalmente para engendrar hijos más que para una vida de razón y actividad en el foro ciudadano. Las mujeres eran criaturas de vida privada; los hombres, de vida pública. Por estas razones, según el historiador Thomas Laqueur el género femenino dejó de verse exactamente como una versión inferior del varón,

21 Porter, "Historia del cuerpo," 277. 
pasando a considerarse en cambio esencialmente diferente pero complementario. Los fisiólogos sostuvieron en ese momento que el aparato reproductor femenino era radicalmente distinto del de los hombres, opinión confirmada por el descubrimiento de la función de los ovarios y la naturaleza del ciclo menstrual.

De hecho, el historiador Edward Shorter considera que las trabas biológicas, (los numerosos embarazos), explican la ancestral servidumbre de la mujer, mientras que las innovaciones biomédicas; es decir, la anticoncepción, el aborto, etcétera, son elementos fundamentales para la emancipación de las mujeres, y que incluso llegan a tener más fuerza que las luchas feministas. ${ }^{22}$

Si la sociedad europea ha sido patriarcal en la longue durée y aún lleva sus marcas, ¿hasta qué punto el patriarcado mismo fue un síntoma directo o una consecuencia de la diferenciación entre cuerpos masculinos y femeninos -una diferencia no simplemente biológica sino instituida dentro de las relaciones sociales-? La razón de la subordinación tradicional de las mujeres a los hombres, ¿fue principal y esencialmente física, debida a que los constantes embarazos impuestos por maridos egoístas en épocas anteriores a la anticoncepción eficaz las encadenaban a los hijos y el hogar, a un envejecimiento prematuro, al agotamiento $\mathrm{y}$, a menudo, a la muerte por enfermedades perinatales y que, además, las encerraban en una cultura de gueto exclusivamente femenina, teñida de sangre menstrual y contaminación del parto?23

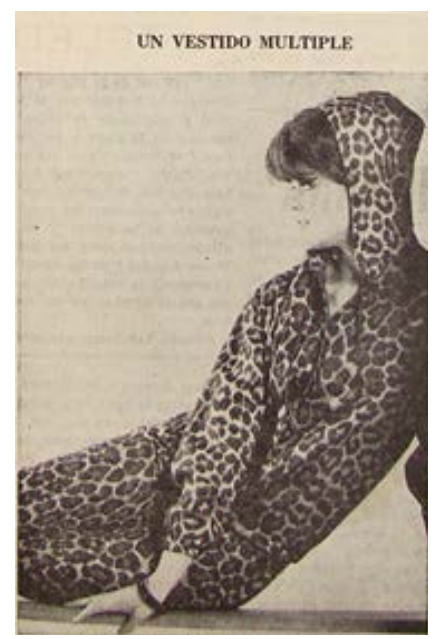

Ilustración 5. Consultorio Sentimental. (11 de Enero de 1964). Sábado, pág. 13

De esta forma, Shorter concluye que, a lo largo del siglo pasado, las mujeres se emanciparon de sus cadenas principalmente biológicas con el advenimiento de las ideas del embarazo sano, la anticoncepción y la legalización del aborto, que, al conceder a las mujeres el control de su propia fertilidad, abrieron el camino a la «familia

22 Cit. En Porter, "Historia del cuerpo," 277-278.

23 Porter, "Historia del cuerpo," 277. 
moderna», la «familia igualitaria»e, incluso, a la sociedad posfamiliar. A pesar de que la publicidad no se refiere a métodos anticonceptivos y mucho menos se evidencian ideas sobre la legalización del aborto, el hecho de que nos digan que este dispositivo está aprobado por la Iglesia nos muestra que ya existía en el Ecuador un debate sobre este tema, y que, probablemente, se distribuían anticonceptivos ante los cuales la Iglesia estaba en contra.

En otro número del Semanario podemos ver que en la columna del "Consultorio Sentimental" aparecen las dudas de un hombre, los redactores explican claramente que este es un espacio dedicado para las mujeres, pero que debido a sus dudas han decido analizarlas. Carlos, el hombre, cuenta que se enamoró alguna vez de una mujer y pensó que era "la mujer de sus sueños"; sin embargo, su familia se opuso ante el amor y no permitió que ambos se casasen. Años después la pareja se volvió a encontrar. Ambos se encontraban casados con otra persona; sin embargo, la mujer se insinúa ante Carlos alegando que nunca fue feliz con su esposo y que cree que esta felicidad pudo y debe dársela Carlos. La respuesta del periódico consiste en que Carlos ha sido un caballero ya que no ha sido impulsivo y decidió primero consultar antes de realizar cualquier acción, y por esta misma condición de caballero y de hombre sabrá resolver su problema "como mejor estime y se acomode a estas sus dos particularidades" ${ }^{24}$. Resulta interesante cómo la condición de hombre les permite tomar decisiones, mientras que a la de mujer se le aclara que no es libre. Se evidencia también cómo la infidelidad llega a ser imperdonable para las mujeres, pero no para los hombres. En el anterior caso se recomendó a Sofía que echara a su posible amante del departamento que alquilaba; sin embargo, en este caso el consejo es que haga lo que más le convenga.

Nos encontramos también con el apartado dedicado a la moda con el título "un vestido múltiple". Este atuendo sirve para usarlo junto con falda, con shorts, o con una blusa, sin mangas, de color negro, para que haga juego con la "piel de leopardo". Esta revolución de la moda es un diseño creado por la Casa de Modas Británica Sportive Casuals Ltd. de Londres. En la parte superior hay una fotografía de una fiesta realizada en el Quito Tenis Club, el 4 de enero de 1964, donde vemos a una pareja disfrazada de payasos recibir un premio. No se sabe qué relación tiene esto con la mujer, pero sí podemos anotar que se enfatiza más en lo que sucede dentro del país que en los acontecimientos externos. Además, encontramos una receta de cocina que consiste en un Pastel de Lenguas y, finalmente, un pequeño poema del escritor paraguayo Miguel Ángel Fernández llamado Los años de la noche.

Después de esta edición la sección "Deténgase aquí mujer" comienza a mantener un formato que duró hasta que el periódico dejó de circular. Este formato consiste en los "consejos", tanto de moda como de belleza, y una receta de cocina; los poemas también siguen formando parte de este nuevo diseño. En algunos casos encontramos 
alguna referencia religiosa, como es el caso de un pequeño resumen historiográfico de la iconografía escultórica de Nuestra Señora, comenzando por la época romántica, pasando por el gótico y llegando a la actualidad. Aparte de este pequeño artículo no encontramos muchos otros relacionados con temas religiosos.

\section{Conclusiones}

A partir de las distintas ediciones de la sección "Deténgase aquí mujer" podemos establecer una serie de conclusiones. En primer lugar, sabemos que a la mujer se la liga principalmente con la vanidad, por lo tanto, cuando los redactores de semanario $S a ́$ bado buscaban llamar la atención de sus lectoras lo hacen a través de consejos, tanto de belleza y de moda. Además de las recetas de cocina, las cuales también resaltan la importancia del rol de esposa fiel y madre, el cual podemos ver evidenciado en varios artículos. También vemos cómo esta sección busca mostrar al público femenino cómo ser mejores mujeres, incluso entrometiéndose en sus cuerpos al resaltar (más de una vez) cuáles son las medidas ideales de un cuerpo perfecto. Esta búsqueda de un perfeccionamiento constante se puede evidenciar a lo largo del semanario, aspecto que dentro del periódico no llega a mostrarse para el sector masculino.

Además de esto, tenemos la decidida repetición de temas religiosos, que tienen una relación mucho más estrecha con las mujeres. En este sentido, notamos que a pesar de que iba en contra de los ideales planteados por el periódico, estos temas debían de ser colocados en esta sección, esto nos muestra que probablemente se concebía al liberalismo como un tema masculino, un tema que debía generar cambios en el ámbito político y público, pero en lo que respecta al sector femenino (que está relacionado con el mundo doméstico), no era preciso generar cambios.

Considero interesante anotar también que la búsqueda de los redactores del periódico por escribir para las mujeres, y, ante todo, por escribir sobre ellas, hemos visto

en algunas secciones de este periódico cómo las mujeres han sido estudiadas e incluso podemos encontrar generalizaciones muy fuertes sobre su ser y su comportamiento. Si comparamos con revistas femeninas actuales podemos encontrar los mismos patrones, quizás ya no exista una relación tan directa con la religión, pero la búsqueda constante de decir cómo ser mejor y la idea de la mujer como objeto de estudio se continúa evidenciando.

\section{Bibliografía}

\section{Fuentes primarias}

Sábado, Ecuador, 1953, 1962, 1964. 


\section{Fuentes secundarias}

Barreiro, Ana Martínez. "La construcción social del cuerpo en las sociedades." $P a$ pers 73, (2004): 127-152.

Catalina, Severo. La mujer: apuntes para un libro. Madrid, 1858.

Clark, Kim. "Género, raza y nación: La protección a la infancia.” En Antología Género. Gioconda Herrera, 183-210. Quito: FLACSO, 2001.

Goetschel, Ana Maria. De Memorias imágenes públicas de las mujeres ecuatorianas de comienzos y fines del siglo XX. Quito: Trama, 2007.

Paz y Miño, Isabel. "Los periódicos que enterré." 50 años de periodismo. Quito: Banco Central del Ecuador, 2010.

Porter, Roy. "Historia del cuerpo." En Formas de hacer historia. Peter Burke, 255286. Madrid: Alianza Editorial, 1993. 